\title{
MENTORING PERFECTION IN MODERN ENTERPRISES CONDITIONS: PRACTICAL RECOMENDATIONS
}

\author{
${ }^{1}$ Alfiya Rafisovna Masalimova, ${ }^{2}$ Neile Kayumovna Schepkina, \\ ${ }^{2}$ Andrei Vasilyevich Leifa, ${ }^{3}$ Albina Rafisovna Shaidullina and ${ }^{2}$ Elena Anatolyevna Burdukovskaya \\ ${ }^{1}$ The Institute of Pedagogy and Psychology of Professional Education of Russian, \\ Academy of Education, Kazan, Isayeva Street, 12, Tatarstan, 420039, Russia \\ ${ }^{2}$ Amur State University, Blagoveschensk, Ignatyevskoe Shosse, 21, Amur Region, 675027, Russia \\ ${ }^{3}$ Almetyevsk State Oil Institute, Almetyevsk, Lenin Street, 2, Tatarstan, 423450, Russia
}

Received 2014-04-10; Revised 2014-04-11; Accepted 2014-06-28

\begin{abstract}
The main idea of this article is to develop practical recommendations for optimization of mentoring at the modern enterprises in Russia, as mentoring as a socio-pedagogical and manufacture phenomenon in the conditions of modern enterprises is the only form of young specialists' corporate training, contributing to inter-firm competition and professional confidentiality fulfillment. However, the interrupted mentoring activities in Russia in the period of transition to market relations had a negative impact on enterprises young personnel corporate training. The presented practical advice for mentors, Advice mentors, as well as for business leaders contribute to the improvement of young personnel corporate training and the mentoring staff activities optimization in modern enterprises of Russia.
\end{abstract}

Keywords: Mentor, Mentoring, The Council of Mentors, Functions and Tasks of Mentoring, Practical Recommendations

\section{INTRODUCTION}

Mentoring becomes an important mechanism that contributes the modern enterprises' competitiveness and at the same time it reduces vocational education shortcomings. The mentoring necessity increases due to the fact that company employees' external training ignores the specifics of a particular enterprise and therefore it has to prepare internal trainers-mentors own professional experience and knowledge, but also inspire the young trainees to reveal their personal and professional potential.

Analysis of psychological-pedagogical and sociological literature on the studied problem allows us to conclude that the principal quantity of scientific researches (Batyshev, 1985; Kozyrin, 1976) on the problem of mentoring was published during the Soviet period 1970among their staff who is able not only to transmit their

1985. The period was characterized by a mass movement of mentoring and represented by itself a system of social and pedagogical influences of the socialist enterprises advanced workers on the consciousness, feelings and will of young workers aimed at their communist ideology, sustained interest and commitment to profession mastering forming, as well as class consciousness and moral satisfaction sense from engaging in manufacture work developing. Prerequisites that resulted to massive movement of mentoring during this period are: The increased quantity of young people at the enterprises of the country; changes in the relationships among people at work under Scientific and Technological Revolution conditions; pedagogical functions' updating of the labor staff (Magura and Kurbatova, 2003).

The generalization of the best experiences in organization of mentoring movement during the Soviet period showed that this time was characterized by the Corresponding Author: Alfiya Rafisovna Masalimova, The Institute of Pedagogy and Psychology of Professional Education of Russian, Academy of Education, Kazan, Isayeva Street, 12, Tatarstan, 420039, Russia 
following aspects: Public organizations activities system on mentoring management was justified; a system of mentors selection and appointment was considered; the structure and the content of mentors psychological and pedagogical training in national universities were developed; the system of mentors activity on selfeducational process is justified; the role of mentoring organization in vocational schools during students' manufacturing practices and spare time having are revealed; the basic requirements on mentoring best experience study, generalization, dissemination and its organization are defined; mentoring principles, functions and methods are defined.

In the 90 s the study of mentoring problems was interrupted due to the following circumstances: Transition to a market economy; priorities and professional values changings; large enterprises closing that resulted to workers and specialists massive layoffs. In connection with this situation the mentoring movement as a means of young professionals' introduction to the profession stopped to exist. However, in the late 90s, some enterprises, solving the problems of their expansion, faced up an urgent need to train a significant number of new employees. So, the mentoring attracts their attention again. In conditions of enterprises transition to innovative development, which requires their industrial, technological and intellectual resources updating, there is an urgent need for mentoring traditions revival.

Mentoring activity having revived its traditions during the modern period in conditions of enterprises computerization and intellectualization is characterizes as fragmentary one and is not based on its combined scientific and methodological support. The level and scale of professional mentors' training and qualification improvement in modern enterprises' conditions are insufficient due to the fact that more than half of the professional knowledge vocational schools graduates have to get directly at the workplace.

\section{MATERIALS AND METHODS}

Terminological dictionary analysis, which was adopted in the theory and practice of mentoring, allowed reveal its essence, its activities direction to young workers vocational training and education as personalities, for their potential development and qualified mentors professional experience transmittal to overcome the information and value barriers in professional activities and their social and professional adaptation.
The goal of modern mentoring is aimed at young workers corporate forming and professional competences development to overcome information and valuable barriers in their professional activities and their social and professional adaptation, as well as their potential revealing with the purpose of their individual professional development trajectories defining.

The objectives of modern mentoring are: Young workers training and education; increasing of productivity at manufacture, new and experienced employees quality improving in accordance with the standards and regulations, which were adopted at the enterprise, young workers corporate culture forming, participation in corporate standards implementation and their continuity ensuring, young workers career opportunities providing, reduction of staff turnover, a cohesive team of the company forming, the company image forming.

Having based on these tasks, the following functions of mentoring activities can be defined:

- Organizational and management function, which means the control of the young employees corporate training process, forestalling management providing, young employees motivation management model's creation, young professionals' team projects management

- Socio-pedagogical function, which aims at socioprofessional adaptation of young professionals, corporate culture and education, their potential revealing for their identity in individual professional development trajectory selecting (Rudavina and Ekomasov, 2011)

- Organizational and methodological function, Which involves the development of training and methodological support of young employees corporate training, mentors training, development of motivations system, effective methods and teaching materials development for young workers training, ratification of regulations on mentoring

- Information and consultation function, which means an effective and systematic transferring of professional knowledge and experience to young employees, the accumulation and enhancement of enterprises advanced experience

- Correction and reorganization function, which is directed on the adjustment and updating of the content and technology of young workers corporate training to be able to meet the modern enterprises requirements 
The above-mentioned objectives, tasks and functions of modern mentoring allow to conclude that this type of activity is directed not only manufactures problems solving, but also solving of psychological-pedagogical problems of young personnel corporate training. Therefore it seems necessary to develop practical recommendations for enterprises aimed at their mentoring systems improving.

\section{RESULTS AND DISCUSSION}

Any modern enterprise should implement and develop mentoring, because this form is not confined to one profile but aimed at achieving different relevant objectives of the enterprise. The following advantages of mentoring activity can be pointed out: The improving of the quality of young workers training at various levels taking into account the real needs and interests of enterprises; reducing of new techniques and technologies mastery time; the creation of a united educational and manufacturing field of the enterprise; reducing of the financial costs on training and staff development (Zamanbekov, 2013; Andreeva and Nechaev, 2013); the acceleration of socio-professional adaptation of new employees to the working conditions at the plant and the mastery of their occupation duties and corporate standards (Tyunikov and Maznichenko, 2005).

However, some problems connected with mentors' corporate training to implement their activities can be pointed out in modern mentoring practice: Insufficient training of mentoring staff to innovative housing reforms in the content and methods of training; rapid obsolescence of scientific and teaching materials, including textbooks; mentors being interested in manufacturing tasks solving.

To improve the process of young staff's corporate training and to optimize mentoring activities in modern enterprises of Russia, practical recommendations for mentors, for the Council of mentors and for enterprises heads are developed:

\subsection{Recommendations for Mentors}

Discussing with a young employee his preferences, interests, abilities and achievements, his specialty, which he got in a high vocational school, novelty, practical relevance, opportunities and feasibility of his final qualifying work results' implementing at the enterprise; the study of the young employee to identify his individual psychological characteristics; introducing the corporate values, enterprise's traditions, administration, mentors, staff and other trainees to a trainee with the aim of his rapid adaptation; introducing the structural units of the company or enterprise to the trainee; assisting the trainee in his study of enterprise's legal and regulatory literature; instructing the trainee about socio-economic characteristics of the region; systematic monitoring of tasks, which were entrusted to a young professional and his timely assistance when he need it; assisting the trainee in his own professional development programs' making; helping young professionals in introspection, organization of their professional development; answering questions of a young employee; forming of a young employee motivation to perform professional activities, to interact with the team; employees learning of regulations and forms of interaction through e-mentoring; trainee teaching of characteristics and possibilities of electronic corporate university; trainee assisting not only in professional and career development, but in personality potential revealing; taking into consideration the trainee not only as a young and inexperienced employee, but also as a potential young professional who is capable to generate new ideas (Masalimova, 2013).

\subsection{Recommendations for Mentors Council}

Organization of the mentors selection procedure in accordance with not only normative criteria (age, length of service in the enterprise, skills level), but also the competency ones (their corporate, research, communication, management, foreign languages, psychological, pedagogical, methodological and coaching competencies); mentors instructing of their functional duties in young employee corporate training; implementation of timely diagnosis of psychological, pedagogical, methodological and coaching competencies forming of mentors; lectures organizing and lecturing, seminars, psychological trainings, debates and roundtables for mentors preparing in order to master the effective teaching technologies in corporate training of young staff; national and international experience of mentoring activities study and dissemination, as well as its adaptive capacity identifying for a particular company; organizational, methodological, informational and consultation help providing for mentors; attracting of mentors and trainees to organize and compete in contest "Best Mentor"; taking into account and assessment of both quantitative indicators (number of trainees, who were trained by mentor) and qualitative ones (mentor's creative initiative, his skills improving) when selecting ways to motivate mentors; new ideas auction organizing, during of which mentors have the opportunity to share 
their experiences of trainees corporate training; regular communication with the trainees about their attitudes to their mentors to identify interpersonal and professional problems they have; explaining of the peculiarities of mentors activities in electronic mentoring, providing transparency of trainees corporate training's and experienced trainers activities' results to mentors, during of which the exchange of professional knowledge and experience occurs; explaining the features in mentors and trainees complementary interaction, involving their professional and complementary cooperation, who is interested not only in their professional duties, but also in other areas of industrial activity; monitoring of young trainee's professional development in order to predict and prevent the risk of his being more intelligent than his mentor; development and improvement of the regulation on mentoring at the enterprise; developing of perspective directions, which can improve the mentoring activity.

\subsection{Recommendations for Managers}

Creation of a unified educational and manufacturing field of the company; regulatory, scientific and methodological support of mentoring activities; social partners search for mentors training courses organizing; integration with high vocational schools in order to select perspective students for their training and work in a particular company; development of regulatory mechanisms of mentors motivation system controlling; selection of experts for enterprise mentors Council, which is based on the following criteria: Management, research, corporate, communication, foreign language, psychological, educational, teaching and coaching competencies; organization of systematic qualification improvement of mentors; controlling over the activities of the mentors Council; coordination of members, who takes part in corporate training dealing with common and private problems of the enterprise; analysis of mentors activities results in achieving the objectives of mentoring; the mentoring process documentation accompanying (publication of the draft order "On mentor appointment "; controlling the development of trainees individual adaptation programs, as well as the completion of the mentoring period); contacting with the mentor and the trainee to provide them with the necessary assistance; constructive use of foreign experience on mentoring activities taking into account the best national traditions of mentoring system; council members' rotation providing for their horizontal and vertical mobility; methodical recommendations develop with the aim of mentoring activities more effectively implementing.
In addition to the presented recommendations aimed at mentoring optimization, the following factors that contribute to the mentoring development at modern enterprises of Russia can be outlined: Organizational (integration with high vocational schools and research institutes, development of professional standards, the creation of corporate universities (Nelson and Phelps, 1966), the formation of the mentoring Institute, the creation of educational and industrial field of the companies, grant programs organization to improve the quality of corporate training), psychological and pedagogical (systematic corporate training of technical professionals to implement mentoring activities, foreign technologies of corporate education practicing, social and psychological counseling of enterprises employees; business training organization, integration of coaching with mentoring, openness to innovation and) (Klucharev and Pahomova, 2008); methodical (individual training plans writing for personnel reserve, the ementoring implementation, distance education of young employees, scientific and methodological support of corporate education, variant programs of professional development implementation).

\section{CONCLUSION}

To improve the modern mentoring activity a great importance should be given to mentors corporate training, as their training is confined only to short-term training in companies that do not reveal in detail andragogic, akmeologic, psychological, educational, scientific-methodological aspects of modern mentoring for beginners in this field. Programs of mentors' corporate training should take into account the needs of enterprises specialists. They must be available for learning as in isolation from job so without separation from professional activities and are aimed at modern mentors psycho-pedagogical, methodological and coach competencies forming. In further research the problem of practical recommendations development on the creation and functioning of effective system of mentors corporate training in the centers of enterprises specialists advanced training is considered to be perspective one.

\section{RECOMMENDATION}

The developed recommendations contain the following benefits: Can be put in the basis of the Regulations on mentoring, determining mentors and the Council instructors activities at enterprises; can be used 
by specialists and heads of educational and industrial centers of the companies; can help the specialists of enterprises, fulfilling mentoring in young personnel corporate training; as well as can be used by the centers of advanced training and retraining of personnel for enterprises.

\section{REFERENCES}

Andreeva, E.S. and A.S. Nechaev, 2013. The mechanism of an innovative development of the industrial enterprise. World Applied Sci. J., 27: 21-23. DOI: 10.5829/idosi.wasj.2013.27.elelc.5

Batyshev, A.S., 1985. Pedagogical System of Mentoring in the Workplace. 1st Edn., Moscow Higher School Press, pp: 272.

Klucharev, G.A. and H.I. Pahomova, 2008. Corporate education: alternative government programs in additional education. J. Continuing Educ. Political Economic Contexts, 3: 134-160.
Kozyrin, Z.A., 1976. Mentoring. 1st Edn., Moscow Higher School Press, pp: 134.

Magura, M.I. and M.B. Kurbatova, 2003. Organization of Training. 1st Edn., SPb Press, pp: 322.

Masalimova, A.R., 2013. Corporate training the trainers: Priority approaches. World Sci. Culture Educ., 4: 96-99.

Nelson, R. and E. Phelps, 1966. Investment in humans, technological diffusion and economic growth. Am. Economic Rev., 56: 69-75.

Rudavina, E.R. and V.V. Ekomasov, 2011. Big Book of HR Director. 1st Edn., Peter Press, pp: 368.

Tyunikov, Y. and M. Maznichenko, 2005. Corporate culture as a factor in the competitiveness of the university. Higher Education Russia J., 10: 69-77.

Zamanbekov, S.Z., 2013. Innovative Development of engineering is a basis of economy modernization of Kazakhstan. Middle-East J. Scientific Res., 16: 1183-1186.

DOI: 